\title{
Myocardial viability and impact of surgical ventricular reconstruction on outcomes of patients with severe left ventricular dysfunction undergoing coronary artery bypass surgery: Results of the Surgical Treatment for Ischemic Heart Failure trial
}

Thomas A. Holly, MD, ${ }^{\mathrm{a}}$ Robert O. Bonow, MD, MS, ${ }^{\mathrm{a}} \mathrm{J}$. Malcolm O. Arnold, MD, ${ }^{\mathrm{b}}$ Jae K. Oh, MD, ${ }^{\mathrm{c}}$ Padmini Varadarajan, MD, ${ }^{\mathrm{d}}$ Gerald M. Pohost, MD, ${ }^{\mathrm{e}}$ Haissam Haddad, MD, ${ }^{\mathrm{f}}$ Robert H. Jones, MD, ${ }^{\mathrm{g}}$ Eric J. Velazquez, MD, ${ }^{\mathrm{g}}$ Bozena Birkenfeld, MD, ${ }^{\mathrm{h}}$ Federico M. Asch, MD, ${ }^{\mathrm{i}}$ Marcin Malinowski, MD, Rodrigo Barretto, MD, ${ }^{\mathrm{k}}$ Renato A. K. Kalil, MD, PhD, ${ }^{1}$ Daniel S. Berman, MD, ${ }^{\mathrm{m}}$ Jie-Lena Sun, MS, Kerry L. Lee, $\mathrm{PhD},{ }^{\mathrm{g}}$ and Julio A. Panza, $\mathrm{MD}^{\mathrm{n}}$

Objectives: In the Surgical Treatment for Ischemic Heart Failure trial, surgical ventricular reconstruction plus coronary artery bypass surgery was not associated with a reduction in the rate of death or cardiac hospitalization compared with bypass alone. We hypothesized that the absence of viable myocardium identifies patients with coronary artery disease and left ventricular dysfunction who have a greater benefit with coronary artery bypass graft surgery and surgical ventricular reconstruction compared with bypass alone.

Methods: Myocardial viability was assessed by single photon computed tomography in 267 of the 1000 patients randomized to bypass or bypass plus surgical ventricular reconstruction in the Surgical Treatment for Ischemic Heart Failure. Myocardial viability was assessed on a per patient basis and regionally according to prespecified criteria.

Results: At 3 years, there was no difference in mortality or the combined outcome of death or cardiac hospitalization between those with and without viability, and there was no significant interaction between the type of surgery and the global viability status with respect to mortality or death plus cardiac hospitalization. Furthermore, there was no difference in mortality or death plus cardiac hospitalization between those with and without anterior wall or apical scar, and no significant interaction between the presence of scar in these regions and the type of surgery with respect to mortality.

Conclusions: In patients with coronary artery disease and severe regional left ventricular dysfunction, assessment of myocardial viability does not identify patients who will derive a mortality benefit from adding surgical ventricular reconstruction to coronary artery bypass graft surgery. ( $\mathrm{J}$ Thorac Cardiovasc Surg 2014;148:2677-84)

\footnotetext{
From the Northwestern University, ${ }^{a}$ Chicago, Ill; University of Western Ontario, ${ }^{b}$ London, Ontario, Canada; Mayo Clinic, ${ }^{c}$ Rochester, Minn; Loma Linda University, ${ }^{\mathrm{d}}$ Loma Linda, Calif; University of Southern California, ${ }^{\mathrm{e}}$ Los Angeles, Calif; Ottawa Heart Institute, ${ }^{f}$ Ottawa, Ontario, Canada; Duke University, ${ }^{\mathrm{g}}$ Durham, NC; Department of Nuclear Medicine PUM, ${ }^{\mathrm{h}}$ Szczecin, Poland; MedStar Washington Hospital Center, ${ }^{\mathrm{i}}$ Washington, DC; Medical University of Silesia, ${ }^{\mathrm{j}}$ Katowice, Poland; Instituto Dante Pazzanese de Cardiologia, ${ }^{\mathrm{k}}$ Sao Paulo, Brazil; Instituto de Cardiologia, ${ }^{1}$ Porto Alegre, Brazil; Cedars-Sinai Medical Center, ${ }^{\mathrm{m}}$ Los Angeles, Calif; and Westchester Medical Center, ${ }^{\mathrm{n}}$ Valhalla, NY.

This work was supported by grants from the National Institutes of Health, National Heart, Lung, and Blood Institute (U01HL69015, UO1HL69013, RO1HL69012).

Disclosures: Dr Bonow reports consulting fees from Gilead. Dr Arnold reports consulting fees from Novartis and lecture fees from Medtronic. Dr Pohost reports grant support from Gilead. Dr Berman reports royalties from Cedars-Sinai Medical Center for the software used for some of the SPECT analysis. Dr Lee reports consulting fees from Cameron Health, Medtronic, and Amgen. All other authors have no disclosures with regard to commercial support.

Received for publication May 30, 2014; accepted for publication June 19, 2014; available ahead of print Aug 22, 2014.

Address for reprints: Thomas A. Holly, MD, Northwestern University Feinberg School of Medicine, 251 East Huron St, Galter 8-134, Chicago, IL 60611 (E-mail: t-holly@northwestern.edu).

$0022-5223 / \$ 36.00$

Copyright (c) 2014 by The American Association for Thoracic Surgery

http://dx.doi.org/10.1016/j.jtcvs.2014.06.090
}

See related commentary on pages 2684-5.

Supplemental material is available online.

The Surgical Treatment for Ischemic Heart Failure (STICH) trial demonstrated that in patients with ischemic cardiomyopathy and anterior wall akinesis undergoing coronary artery bypass grafting (CABG), the addition of surgical ventricular reconstruction (SVR) was not associated with a reduction in the rate of death or hospitalization for cardiac causes compared with results of CABG alone. ${ }^{1}$ All patients in the SVR hypothesis of STICH were required to have global left ventricular (LV) dysfunction (ejection fraction $\leq 35 \%$ ) and regional dysfunction with anterior 


\section{Abbreviations and Acronyms \\ $\mathrm{CABG}=$ coronary artery bypass grafting \\ $\mathrm{CAD}=$ coronary artery disease \\ $\mathrm{LV}=$ left ventricular \\ SPECT $=$ single photon emission computed tomography \\ STICH $=$ Surgical Treatment for Ischemic Heart Failure \\ SVR = surgical ventricular reconstruction}

akinesia or dyskinesia, as determined by the recruiting investigators. However, whether these dysfunctional segments were composed of scarred or viable myocardium was not analyzed in the original report, because systematic application of a dedicated test for myocardial viability was not part of the original study design or a determinant of treatment assignment.

Although viable myocardium is expected to recover after revascularization, scarred tissue is not. Further, a large amount of scarred myocardium may contribute negatively to overall $\mathrm{LV}$ function by accelerating or worsening the process of remodeling and by reducing the mechanical contribution of normal or viable myocardium via tethering of adjacent segments. Therefore, excluding scarred anterior wall segments through SVR could result in hemodynamic and clinical improvement. Conversely, identification of myocardial viability in the same areas could lead to the retention of segments with the potential to recover after revascularization without SVR and contribute to improved LV mechanical function. Accordingly, distinguishing between viable versus scarred myocardium in the LV territory targeted for reconstruction may be critical for the success of the procedure and could identify a population who will preferentially benefit from SVR.

Single photon emission computed tomography (SPECT) is commonly performed in patients with LV dysfunction being considered for revascularization to identify areas of viable and scarred myocardium. Therefore, we tested in the STICH population the hypothesis that the presence of myocardial scar on SPECT identifies patients with coronary artery disease (CAD) and LV dysfunction who have the greatest benefit with $\mathrm{CABG}+\mathrm{SVR}$ compared with $\mathrm{CABG}$ alone.

\section{METHODS \\ Study Design}

The rationale and design of the STICH trial have been described,,${ }^{1-3}$ as have the methods of the viability substudy of the STICH revascularization hypothesis. ${ }^{4}$ STICH was a multicenter, nonblinded, randomized trial sponsored by the National Heart, Lung, and Blood Institute. A total of 2136 patients were enrolled at 127 sites in 26 countries, all of whom were candidates for CABG. STICH involved 2 hypotheses regarding the role of surgery in patients with LV systolic dysfunction. All patients in STICH were eligible for CABG on the basis of clinical and coronary angiographic findings. The STICH revascularization hypothesis enrolled patients who were candidates for CABG or medical therapy, thus excluding patients with left main disease or unstable angina. ${ }^{3}$ The STICH SVR hypothesis enrolled patients who were candidates for CABG who also had severe regional dysfunction of the LV anterior wall and were eligible for SVR. ${ }^{1}$ In this arm of the trial, 1000 patients were enrolled, of whom 499 were assigned to CABG alone and 501 were assigned to CABG plus SVR. Myocardial viability testing was performed using SPECT in 267 of the 1000 patients, of whom 126 were assigned to CABG alone and 141 were assigned to CABG plus SVR. An independent core laboratory funded by the National Heart, Lung, and Blood Institute, in which investigators were unaware of study group assignments and the individual characteristics of patients, coordinated data collection and analysis for the SPECT studies.

\section{Study Procedures}

Four different clinically validated SPECT protocols for assessing myocardial viability were permitted at the enrolling sites. These included thallium imaging using a rest-redistribution or stress-rest-reinjection protocol, ${ }^{5}$ a dual isotope protocol with rest-redistribution thallium imaging plus stress imaging with a technetium-99m perfusion tracer, ${ }^{6}$ or imaging with a technetium-99m tracer at rest after the administration of nitroglycerin. ${ }^{7}$ Images were stored digitally and sent to the STICH Radionuclide Core Laboratory at Northwestern University for analysis. Core laboratory measurement of regional tracer activity was performed on all SPECT studies using a 17-segment model of the left ventricle. ${ }^{8}$ A myocardial segment was deemed viable if the tracer activity in that segment was $50 \%$ or greater of the activity in the segment with maximal activity. For thallium rest-redistribution imaging, a segment with activity less than $50 \%$ of the maximal myocardial activity on the redistribution images was also defined as viable if the improvement in activity from the rest to redistribution images was $12 \%$ or greater. Segments not meeting these criteria for viability were deemed to be scarred.

Myocardial viability on a per-patient basis was prospectively defined as the presence of 11 or more viable segments $(\geq 65 \%$ of the entire left ventricle). When 7 or more segments were nonviable ( $\geq 41 \%$ of the left ventricle), the patient was considered to have insufficient mass of viable myocardium. This threshold was selected on the basis of previous retrospective data indicating that the likelihood for functional improvement after $\mathrm{CABG}$ is low when more than $40 \%$ of the $\mathrm{LV}$ myocardium is nonviable. ${ }^{9}$

Because the SVR procedure involves reconfiguring the anteroapical wall, we specifically explored the impact of anterior wall and apical scarring on the outcomes with CABG alone and CABG + SVR. For this analysis, viability was assessed using a 5-segment model in which the left ventricle was divided into septal, inferior, lateral, anterior, and apical segments (Figure E1).

\section{Patient Follow-up and Outcomes}

After enrollment, patients were followed every 4 months for the first year and every 6 months thereafter. The primary outcome was the composite of death from any cause or hospitalization for cardiovascular causes. The secondary end point was death from any cause. Definitions of the trial end points have been reported. ${ }^{3}$ All end points were adjudicated by an independent clinical events committee. The comparisons of outcomes that were related to treatment were based on intention-to-treat analyses. Analyses that were based on actual treatment received were also performed to account for crossovers.

\section{Statistical Analysis}

Baseline patient characteristics are summarized as percentages for categoric variables and means and standard deviations for continuous variables. Comparisons of baseline data between (a) patients with and without a viability test, and (b) patients with and without myocardial viability, given that a test was obtained, were performed using the Pearson chi-square test for categoric variables and the Wilcoxon rank-sum test for continuous variables. Kaplan-Meier event curves for mortality and for death or cardiac 
TABLE 1. Baseline characteristics of patients in Surgical Treatment for Ischemic Heart Failure surgical ventricular reconstruction hypothesis with and without viability testing: Clinical characteristics

\begin{tabular}{|c|c|c|c|}
\hline Variable & $\begin{array}{c}\text { Patients } \\
\text { with a } \\
\text { viability } \\
\text { test }(\mathbf{n}=\mathbf{2 6 7}) \\
\end{array}$ & $\begin{array}{c}\text { Patients } \\
\text { without a } \\
\text { viability test } \\
(\mathbf{n}=\mathbf{7 3 3}) \\
\end{array}$ & $\begin{array}{c}P \\
\text { value } \\
\end{array}$ \\
\hline Age, mean \pm SD & $61.3 \pm 9.5$ & $61.8 \pm 9.8$ & .627 \\
\hline Female, n (\%) & $40(15.0)$ & 107 (14.6) & .880 \\
\hline Diabetes, n (\%) & $77(28.8)$ & $267(36.4)$ & .026 \\
\hline Hyperlipidemia, n (\%) & $184(69.4)$ & $534(73.0)$ & .275 \\
\hline Hypertension, n (\%) & $132(49.4)$ & $453(61.8)$ & $<.001$ \\
\hline Current smoker, n (\%) & $50(18.7)$ & $167(22.8)$ & .169 \\
\hline $\begin{array}{l}\text { Chronic renal insufficiency, } \\
\mathrm{n}(\%)\end{array}$ & $21(7.9)$ & $64(8.7)$ & .671 \\
\hline $\begin{array}{l}\text { Atrial flutter/fibrillation, } \\
\mathrm{n}(\%)\end{array}$ & $28(10.5)$ & $89(12.1)$ & .471 \\
\hline $\begin{array}{l}\text { Peripheral vascular disease, } \\
\mathrm{n}(\%)\end{array}$ & $37(13.9)$ & 109 (14.9) & .688 \\
\hline $\begin{array}{l}\text { Prior myocardial infarction, } \\
\quad \mathrm{n}(\%)\end{array}$ & $237(88.8)$ & 635 (86.6) & .372 \\
\hline $\begin{array}{l}\text { Risk-at-randomization score, }{ }^{*} \\
\text { median }(\mathrm{Q} 1, \mathrm{Q} 3)\end{array}$ & $10.0(4.0,19.0)$ & $13.0(6.0,22.0)$ & .002 \\
\hline Previous PCI, n (\%) & $67(25.1)$ & $128(17.5)$ & .007 \\
\hline Previous CABG, n (\%) & $2(0.7)$ & $22(3.0)$ & .040 \\
\hline Previous ICD, n $(\%)$ & $5(1.9)$ & $29(4.0)$ & .108 \\
\hline CCS angina class, $\mathrm{n}(\%)$ & & & .001 \\
\hline No angina & $51(19.1)$ & $198(27.0)$ & \\
\hline I & $20(7.5)$ & $51(7.0)$ & \\
\hline II & $72(27.0)$ & $116(15.8)$ & \\
\hline III & $106(39.7)$ & $302(41.2)$ & \\
\hline IV & $18(6.7)$ & $66(9.0)$ & \\
\hline NYHA HF class, n (\%) & & & $<.001$ \\
\hline I & $20(7.5)$ & $66(9.0)$ & \\
\hline II & $154(57.7)$ & $275(37.5)$ & \\
\hline III & $80(30.0)$ & $348(47.5)$ & \\
\hline IV & $13(4.9)$ & $44(6.0)$ & \\
\hline Blood pressure, mean \pm SD & & & .007 \\
\hline Systolic & $117.7 \pm 15.7$ & $121.6 \pm 18.1$ & \\
\hline Diastolic & $73.9 \pm 9.9$ & $73.3 \pm 11.7$ & \\
\hline Heart rate, mean $\pm \mathrm{SD}$ & $72.1 \pm 11.9$ & $72.7 \pm 14.0$ & .628 \\
\hline Creatinine (mg/dL) & $1.1 \pm 0.4$ & $1.1 \pm 0.4$ & .324 \\
\hline \multicolumn{4}{|l|}{ CAD distribution, $\mathrm{n}(\%)$} \\
\hline Left main $(\geq 50 \%)$ & $42(15.7)$ & $155(21.1)$ & .057 \\
\hline No. of vessels $>50 \%$ & & & .084 \\
\hline 1-Vessel & $32(12.0)$ & $55(7.5)$ & \\
\hline 2-Vessel & $70(26.2)$ & $205(28.0)$ & \\
\hline 3-Vessel & $165(61.8)$ & $473(64.5)$ & \\
\hline Previous CABG, $\mathrm{n}$ & 2 & 22 & .007 \\
\hline \multicolumn{4}{|l|}{ Bypass graft status, $\mathrm{n}(\%)$} \\
\hline$\geq 1$ Stenosed or occluded & $2(100)$ & $18(81.8)$ & \\
\hline$\geq 1$ Occluded & $2(100)$ & $15(68.2)$ & \\
\hline $\mathrm{LVEF}$, mean $\pm \mathrm{SD}$ & $27.3 \pm 5.5$ & $26.8 \pm 6.0$ & .236 \\
\hline $\mathrm{EDVI} \mathrm{mL} / \mathrm{m}^{2}$, mean $\pm \mathrm{SD}$ & $122.7 \pm 46.4$ & $114.9 \pm 40.8$ & .045 \\
\hline $\mathrm{ESVI} \mathrm{mL} / \mathrm{m}^{2}$, mean $\pm \mathrm{SD}$ & $87.6 \pm 39.5$ & $90.2 \pm 36.4$ & .027 \\
\hline ACEI/ARB & $246(92.1)$ & $633(86.4)$ & .013 \\
\hline Beta-blocker & $232(86.9)$ & $576(78.6)$ & .551 \\
\hline
\end{tabular}

TABLE 1. Continued

\begin{tabular}{|c|c|c|c|}
\hline Variable & $\begin{array}{c}\text { Patients } \\
\text { with a } \\
\text { viability } \\
\text { test }(n=267)\end{array}$ & $\begin{array}{c}\text { Patients } \\
\text { without a } \\
\text { viability test } \\
(\mathbf{n}=\mathbf{7 3 3})\end{array}$ & $\begin{array}{c}P \\
\text { value }\end{array}$ \\
\hline Amiodarone & $31(11.6)$ & $93(12.7)$ & .648 \\
\hline Aspirin & $215(80.5)$ & $593(80.9)$ & .084 \\
\hline Warfarin & $26(9.7)$ & $96(13.1)$ & .151 \\
\hline Clopidogrel & $19(7.1)$ & $62(8.5)$ & .491 \\
\hline Digoxin & $43(16.1)$ & $114(15.6)$ & .832 \\
\hline Diuretic (loop/thiazide) & $143(53.6)$ & $452(61.7)$ & .021 \\
\hline Diuretic (potassium sparing) & $112(41.9)$ & $259(35.3)$ & .056 \\
\hline Nitrate & $165(61.8)$ & $422(57.6)$ & .230 \\
\hline Statin & $230(86.1)$ & $541(73.8)$ & $<.001$ \\
\hline \multicolumn{4}{|c|}{$\begin{array}{l}A C E I \text {, Angiotensin-converting enzyme inhibitor; } A R B \text {, angiotensin receptor } \\
\text { blocker; } C A B G \text {, coronary artery bypass grafting; } C A D \text {, coronary artery disease; } \\
E D V I \text {, end-diastolic volume index; } E S V I \text {, end-systolic volume index; } I C D \text {, implant- } \\
\text { able cardiac defibrillator; } L V E F \text {, left ventricular ejection fraction; NYHA } H F \text {, } \\
\text { New York Heart Association heart failure; } P C I \text {, percutaneous coronary intervention; } \\
S D \text {, standard deviation; } C C S \text {, Canadian Cardiovascular Society. *The risk-at- } \\
\text { randomization score ranges from } 1 \text { to } 32 \text {, with higher numbers indicating a higher pre- } \\
\text { dicted rate of death. }\end{array}$} \\
\hline
\end{tabular}

hospitalization were created and displayed by groups, and the log-rank test was used to statistically compare groups with respect to these outcomes.

Among the patients with viability assessment, unadjusted and adjusted Cox proportional hazards regression models were used to examine the association between the status of myocardial viability and the outcomes of death and death or cardiac hospitalization. The adjustment variables were baseline clinical factors, including age, creatinine, atrial fibrillation/ flutter, diabetes, mitral regurgitation, and end-systolic volume index, known from previous analyses to be key prognostic factors.

The Cox model was also used to examine the association between the randomized treatments (CABG vs CABG + SVR) and the 2 outcomes, death and death or cardiac hospitalization, in patients with and without viable myocardium. Hazard ratios and $95 \%$ confidence intervals for the treatment comparisons were generated using the Cox model. The Cox model was also used to test for an interaction between treatment and viability, that is, whether there was a different effect of CABG + SVR compared with CABG alone in patients with versus those without viability. These analyses were performed for overall LV viability, anterior wall viability, apex viability, and the anterior wall and apex combined. All statistical tests were 2-sided. All statistical analyses were performed using SAS statistical software, version 9.2 (SAS Institute Inc, Cary, NC).

\section{RESULTS}

\section{Study Population}

Among the 267 patients with a viability assessment, 227 were men and 40 were women. The mean age was $61 \pm 9$ years, the mean LV ejection fraction was $27 \% \pm 5 \%$, and $89 \%$ of patients had a previous myocardial infarction. Table 1 shows a comparison of the baseline characteristics of the patients who underwent a SPECT viability study and those who did not. Both groups were similar in age, gender, history of myocardial infarction, CAD distribution, and ejection fraction. Of note, the patients who underwent viability testing less often had a history of diabetes, hypertension, or prior $\mathrm{CABG}$ and more often had undergone prior percutaneous coronary intervention. Those who did not undergo viability testing had a higher clinical 
TABLE 2. Baseline characteristics of patients who underwent viability testing: Clinical characteristics

\begin{tabular}{|c|c|c|c|}
\hline Variable & $\begin{array}{c}\text { Patients } \\
\text { without } \\
\text { myocardial } \\
\text { viability }(\mathbf{n}=76) \\
\end{array}$ & $\begin{array}{c}\text { Patients with } \\
\text { myocardial } \\
\text { viability } \\
(\mathbf{n}=191) \\
\end{array}$ & $\begin{array}{c}P \\
\text { value }\end{array}$ \\
\hline Age, $y$, mean $\pm S D$ & $61.7 \pm 8.7$ & $61.1 \pm 9.8$ & .704 \\
\hline Female, n (\%) & $7(9.2)$ & $33(17.3)$ & .096 \\
\hline $\begin{array}{l}\text { Prior myocardial infarction, } \\
\mathrm{n}(\%)\end{array}$ & $72(94.7)$ & $165(86.4)$ & .051 \\
\hline $\begin{array}{l}\text { Risk-at-randomization } \\
\text { score,* median (Q1, Q3) }\end{array}$ & $11.0(5.0,21.0)$ & $10.0(4.0,19.0)$ & .526 \\
\hline CCS angina class, $\mathrm{n}(\%)$ & & & .614 \\
\hline No angina & $13(17.1)$ & $38(19.9)$ & \\
\hline I & $3(3.9)$ & $17(8.9)$ & \\
\hline II & $23(30.3)$ & $49(25.7)$ & \\
\hline III & $31(40.8)$ & $75(39.3)$ & \\
\hline IV & $6(7.9)$ & $12(6.3)$ & \\
\hline $\begin{array}{r}\text { Highest NYHA HF class } \\
\text { within } 3 \mathrm{mo}, \mathrm{n}(\%)\end{array}$ & & & .622 \\
\hline I & $2(2.6)$ & $8(4.2)$ & \\
\hline II & $30(39.5)$ & $64(33.5)$ & \\
\hline III & $34(44.7)$ & $84(44.0)$ & \\
\hline IV & $10(13.2)$ & $35(18.3)$ & \\
\hline ACEI/ARB & $72(94.7)$ & $174(91.1)$ & .319 \\
\hline Beta-blocker & $66(86.8)$ & $166(86.9)$ & .988 \\
\hline Aspirin & $62(81.6)$ & $153(80.1)$ & .784 \\
\hline Statin & $67(88.2)$ & $163(85.3)$ & .548 \\
\hline \multicolumn{4}{|l|}{ CAD distribution, $\mathrm{n}(\%)$} \\
\hline Left main $(\geq 50 \%)$ & $13(17.1)$ & $29(15.2)$ & .697 \\
\hline No. of vessels $>75 \%$ & & & .838 \\
\hline None & $1(1.3)$ & $5(2.6)$ & \\
\hline 1-Vessel & $18(23.7)$ & $42(22.0)$ & \\
\hline 2-Vessel & $29(38.2)$ & $81(42.4)$ & \\
\hline 3-Vessel & $28(36.8)$ & $63(33.0)$ & \\
\hline LVEF, mean \pm SD & $27.6 \pm 5.41$ & $27.2 \pm 5.52$ & .649 \\
\hline $\mathrm{EDVI} \mathrm{mL} / \mathrm{m}^{2}$, mean $\pm \mathrm{SD}$ & $143.1 \pm 53.23$ & $114.6 \pm 40.83$ & $<.001$ \\
\hline $\mathrm{ESVI} \mathrm{mL} / \mathrm{m}^{2}$, mean $\pm \mathrm{SD}$ & $111.9 \pm 47.51$ & $84.6 \pm 38.18$ & $<.001$ \\
\hline
\end{tabular}

risk at the time of randomization, as assessed using an equation derived in an independent dataset from multiple variables with known power to predict 5-year risk of death without CABG. ${ }^{10}$

\section{Myocardial Viability, Scar, and Outcomes}

Myocardial viability was identified in $191(72 \%)$ of the study patients; the remaining 76 were classified as nonviable. Table 2 shows a comparison of the baseline characteristics of the patients with and without myocardial viability. Patients with and without viability were similar in age $(61 \pm$ 10 years vs $62 \pm 9$ years $)$ and ejection fraction $(27 \% \pm 6 \%$ vs $28 \% \pm 5 \%$ ). Patients without viability had larger LV end- diastolic and end-systolic volume indices than those with viability ( $143 \pm 53$ vs $115 \pm 41 \mathrm{~mL} / \mathrm{m}^{2}$ and $112 \pm 48$ vs $85 \pm 38 \mathrm{~mL} / \mathrm{m}^{2}$, respectively; both $P<.0001$ ).

When treatment allocation was not considered, there was no significant difference in mortality between patients with and without viability $(19 \%$ vs $22 \%$ at 3 years, $P=.84)$ (Figure $1, A$ ) or in the combined outcome of death or cardiac hospitalization ( $48 \%$ vs $62 \%$ at 3 years, $P=.17$ ) (Figure 1, B).

Of the 267 patients with a viability test, predominantly nonviable myocardium was identified in the anterior wall or apex in $221(83 \%)$. At 3 years, there was no difference in mortality between those with and without nonviable myocardium in the anterior wall $(19 \%$ vs $21 \%$, respectively, $P=.85)$, apex (20\% vs $23 \%$, respectively, $P=.96)$, or the combined anterior wall and apex ( $20 \%$ vs $22 \%$, respectively, $P=.89$ ). There was also no difference between those with viable versus nonviable myocardium in these territories for the combined outcome of death or cardiac hospitalization.

\section{Interaction Between Myocardial Viability and Treatment}

Among the 191 patients with myocardial viability, 99 $(52 \%)$ underwent CABG + SVR and $92(48 \%)$ underwent CABG alone. Of the 76 patients without viability, $42(55 \%)$ underwent $\mathrm{CABG}+\mathrm{SVR}$ and $34(45 \%)$ underwent CABG alone. There was no significant interaction between global myocardial viability status and the treatment effect of $\mathrm{CABG}+\mathrm{SVR}$ versus $\mathrm{CABG}$ alone with respect to mortality $(P=.36)$ (Figure $2, A)$ or death plus cardiac hospitalization $(P=.55)$ (Figure $2, B)$.

When regional viability was considered, there was no significant interaction between the presence or absence of viable myocardium in the anterior region and the type of surgery with respect to mortality $(P=.12)$ (Figure $3, A)$. There was no significant interaction between the presence or absence of scar in the apical region and the treatment effect of CABG + SVR versus CABG alone with respect to mortality $(P=.55)$ (Figure $3, B)$ or death or cardiovascular hospitalization $(P=.70)$. Similar to the findings in the apex, there was no significant interaction between the presence or absence of viable myocardium in the combined anterior wall and apex and the type of surgery with respect to mortality $(P=.78)$ (Figure 3, $C)$ or death or cardiovascular hospitalization $(P=.67)$.

\section{DISCUSSION}

The original results of the SVR hypothesis of the STICH trial demonstrated no survival benefit in adding SVR to CABG. ${ }^{1}$ Uncertainty persists on whether certain subgroups of patients may benefit from SVR, such as those with larger LV volumes or those with evidence of scar in the anteroapical region. ${ }^{11,12}$ In this substudy of the STICH trial, we demonstrated that an overall assessment of 


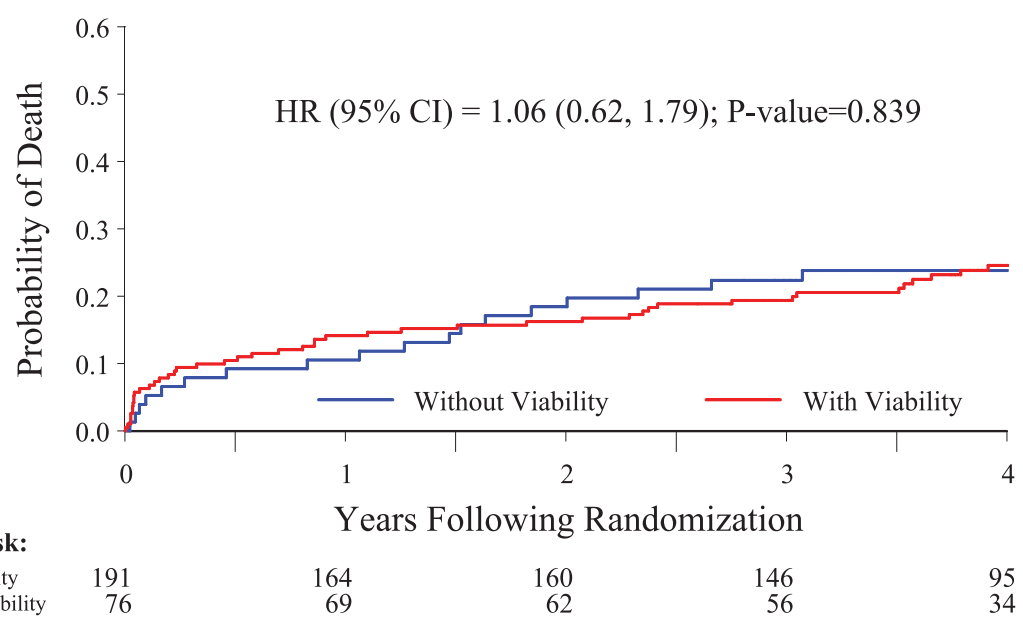

A

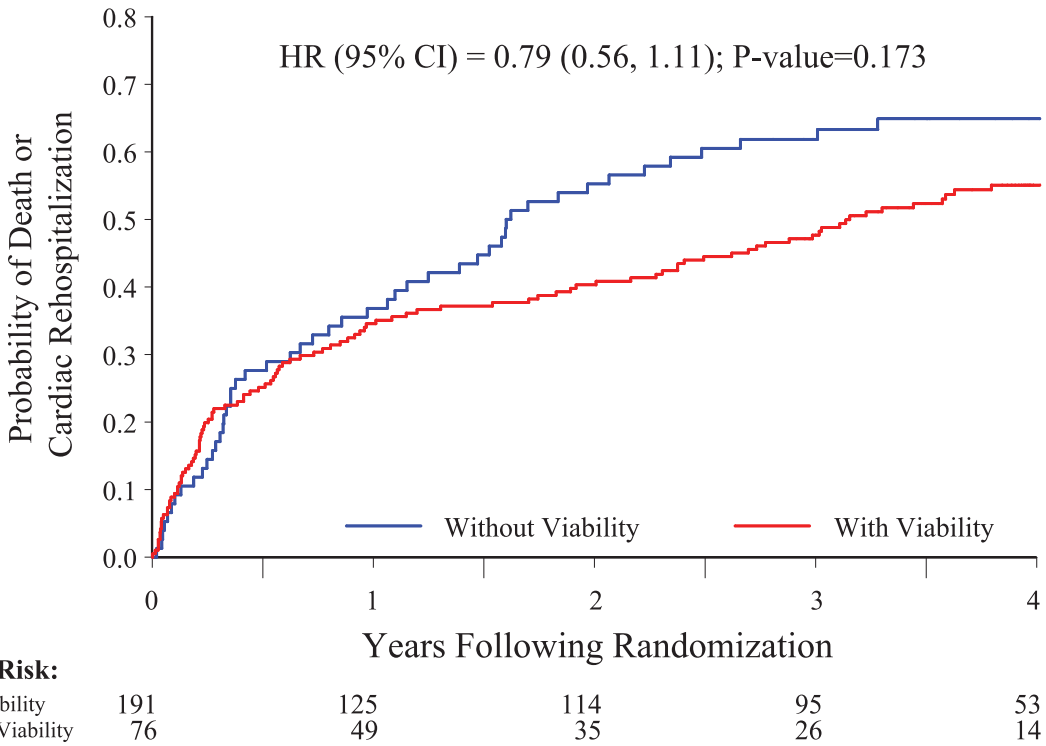

\begin{tabular}{lrrrrr} 
No. at Risk: & \multicolumn{1}{c}{} & & \\
With Viability & 191 & 125 & 114 & 95 & 53 \\
Without Viability & 76 & 49 & 35 & 26 & 14
\end{tabular}

B

FIGURE 1. Kaplan-Meier estimates of the probability of death (A) and death or cardiovascular hospitalization (B) according to myocardial viability status. $C I$, Confidence interval; $H R$, hazard ratio.

myocardial viability with SPECT imaging does not help predict which patients will be alive or free from cardiac hospitalization 3 years after undergoing CABG or $\mathrm{CABG}+\mathrm{SVR}$ or which patients will benefit more from performing concomitant SVR at the time of CABG. Furthermore, specifically identifying nonviable myocardium in the anterior wall and apex did not help determine which patients would derive a survival benefit with SVR.

Our findings are similar to those of the viability substudy of the STICH revascularization hypothesis, in which the results of viability testing with SPECT or dobutamine echocardiography were not associated with benefit from adding CABG to optimal medical therapy. ${ }^{4}$ However, it must be noted that this study addressed a completely different issue, namely, whether the presence of myocardial viability or scar was associated with benefit from SVR in patients in whom the decision for surgical revascularization had already been made. Thus, in these patients, the myocardial viability information would not be used to aid in the decision between medical therapy alone or medical therapy plus revascularization. Instead, the potential value of noninvasive testing would derive from identifying areas without viability (or with scar) that may be surgically excluded from the LV cavity at the time of surgery to improve LV performance and, ultimately, patient outcomes. In this context, the results observed with the assessment of global LV viability are not necessarily surprising and suggest that this form of imaging is not helpful for the selection of patients who benefit from adding SVR to 
With Viability

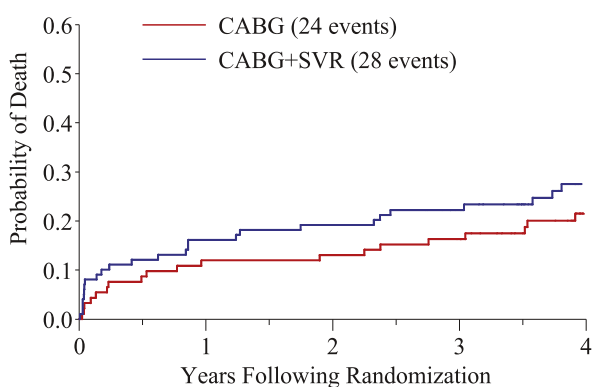

No. at Risk CABG CABG+SVR

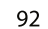

99

\section{1}

\section{0}

\section{6}

48
Without Viability

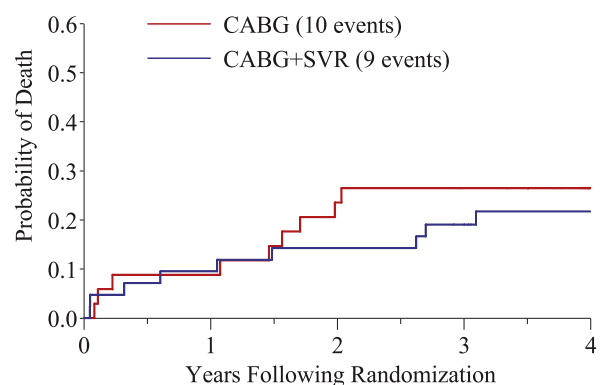

Sub-group

With Viability

Without Viability

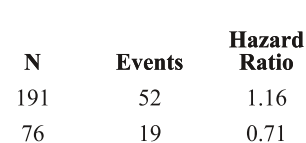

Interaction with Treatment P-value $=0.363$

A

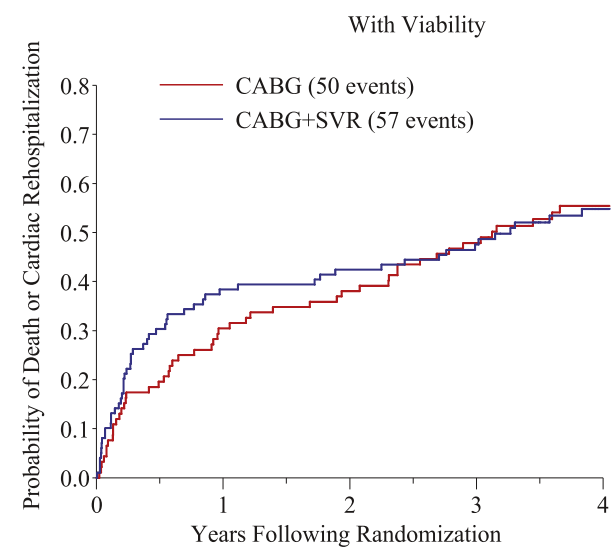

$\begin{array}{llllll}\text { No. at Risk } & & & & & \\ \text { CABG } & 92 & 64 & 57 & 47 & 23 \\ \text { CABG+SVR } & 99 & 61 & 57 & 48 & 30\end{array}$

CABG+SVR

61

$\begin{array}{cc}\text { Events } & \begin{array}{c}\text { Hazard } \\ \text { Ratio }\end{array} \\ 107 & 1.12 \\ 49 & 0.90\end{array}$

Sub-group

With Viability

Without Viability

Interaction with Treatment

P-value $=0.553$
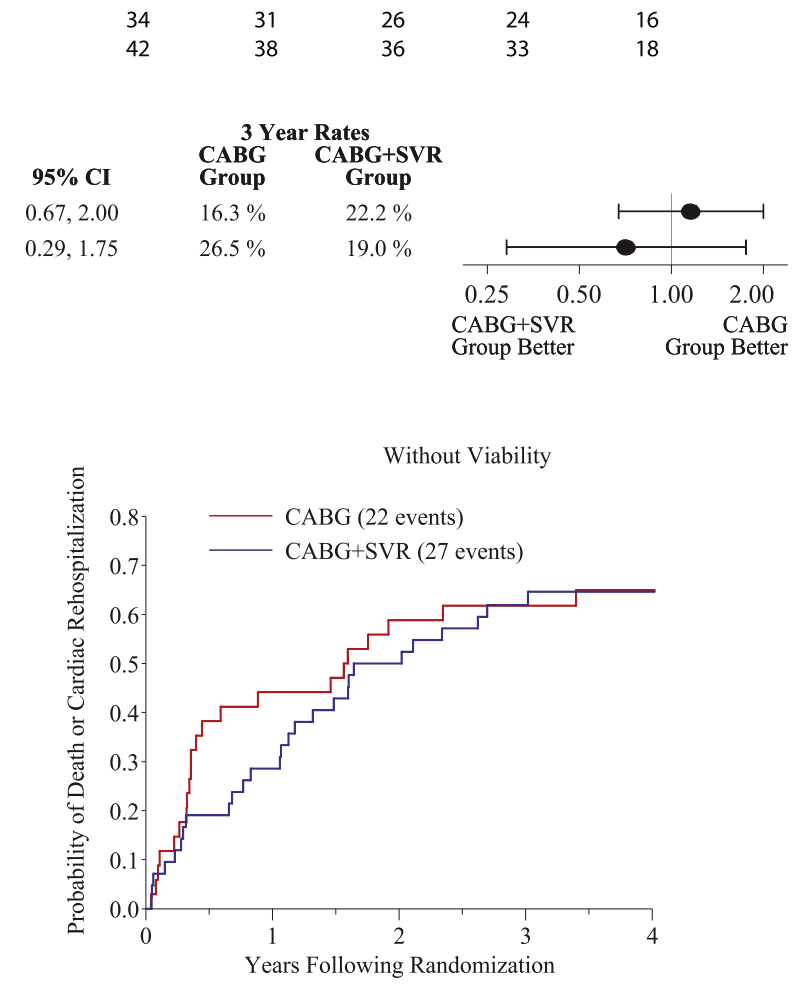

Without Viability

$\begin{array}{lllll}34 & 19 & 14 & 12 & 6 \\ 42 & 30 & 21 & 15 & 8\end{array}$

\begin{tabular}{lc}
\multicolumn{2}{c}{ 3 Year Rates } \\
CABG & $\begin{array}{c}\text { CABG+SVR } \\
\text { Group }\end{array}$ \\
Group & $47.6 \%$ \\
$47.8 \%$ & $61.9 \%$ \\
$61.8 \%$ & 0
\end{tabular}

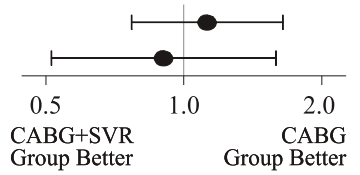

B

FIGURE 2. Kaplan-Meier estimates of the probability of death (A) and death or cardiovascular hospitalization (B) according to myocardial viability status and treatment. $C A B G$, Coronary artery bypass grafting; $C I$, confidence interval; SVR, surgical ventricular reconstruction.

CABG. It must be noted that previous studies of patient outcomes with SVR did not report incorporation of viability testing into the decision for SVR. ${ }^{13}$ Thus, it is unclear what role noninvasive studies have played in the selection of patients by other investigators.
On the basis of the study design requiring all patients to be eligible to undergo the SVR procedure, it was expected that the majority of patients $(82 \%$ in the present study) demonstrated evidence of scar on the apical segments. However, only $25 \%$ of the patients 

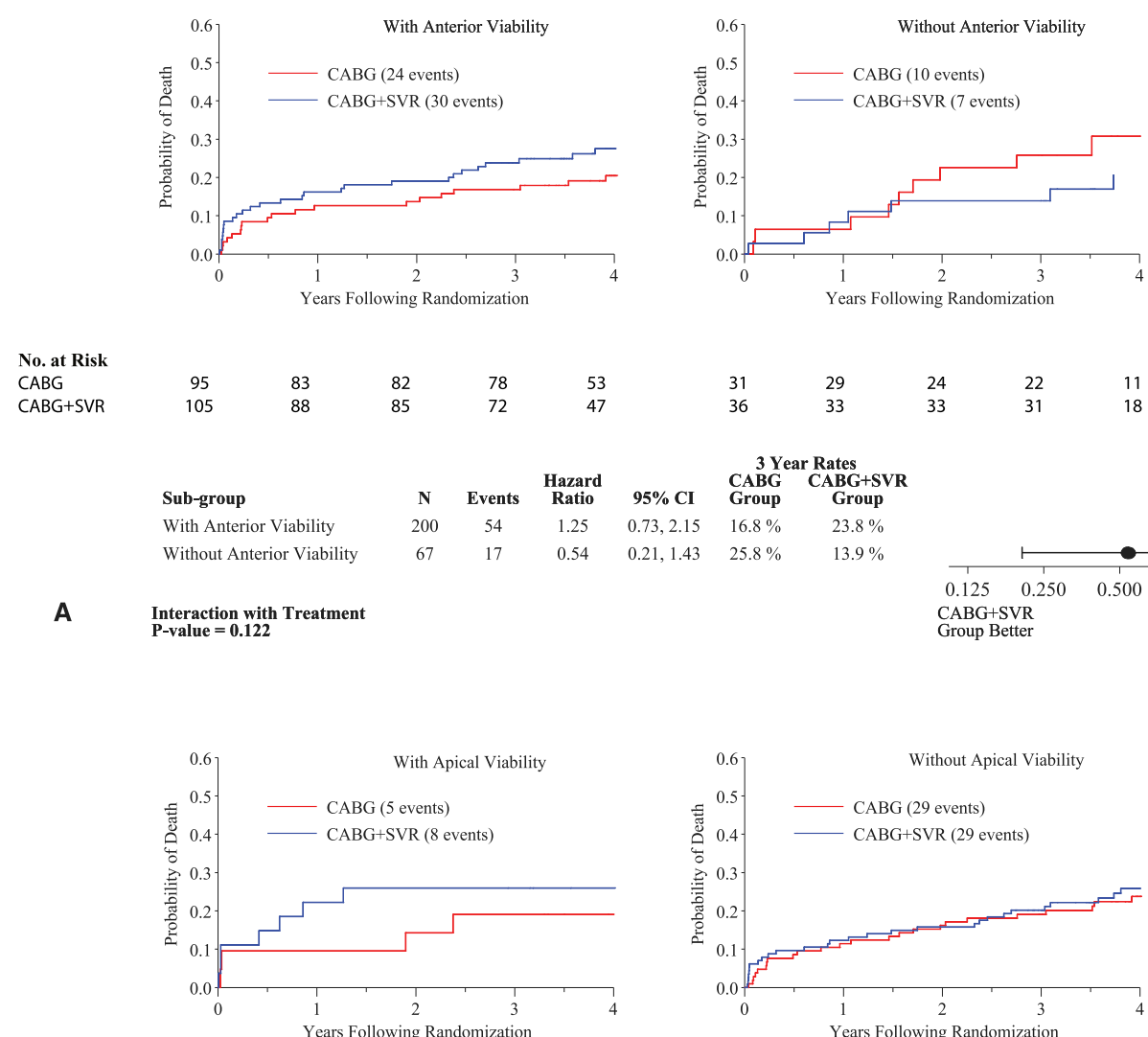

No. at Risk
CABG

CABG

$\begin{array}{lllll}21 & 19 & 18 & 17 & 12 \\ 27 & 21 & 20 & 19 & 16\end{array}$
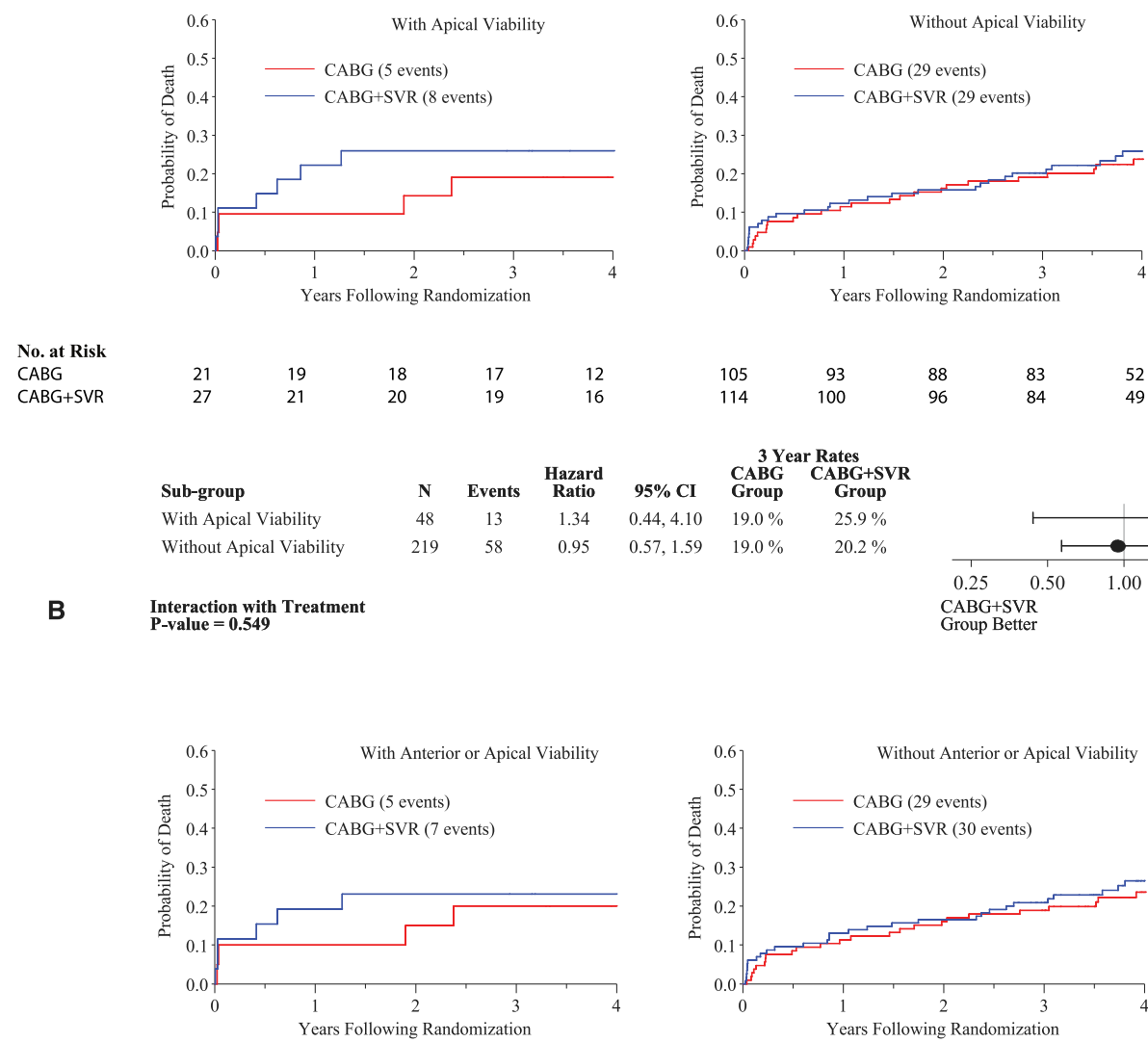

B Interaction with Treatment
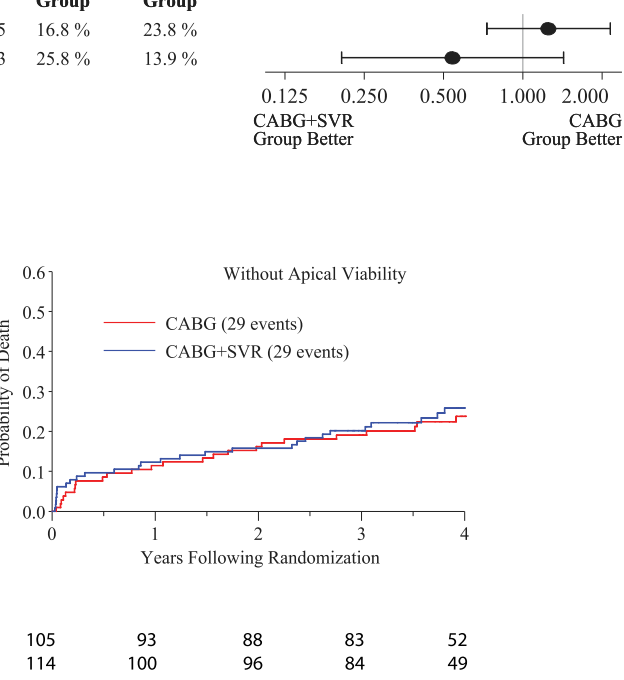

No. at Risk

CABG

CABG+SVR

$\begin{array}{lllll}20 & 18 & 17 & 16 & 12 \\ 26 & 21 & 20 & 19 & 16\end{array}$
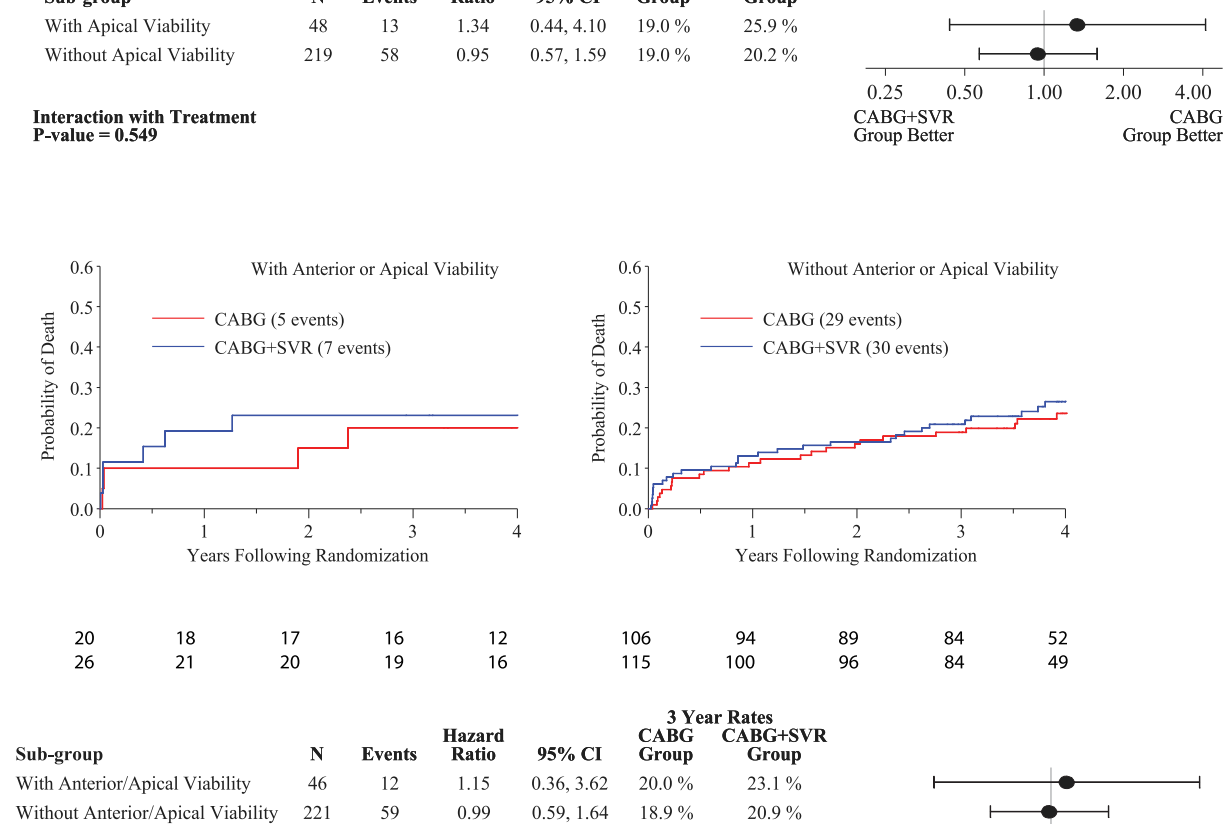

C Interaction with Treatment $0.59,1.64$

$18.9 \%$

$20.9 \%$

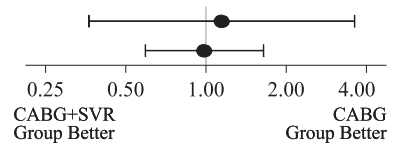

FIGURE 3. Kaplan-Meier estimates of the probability of death according to anterior wall myocardial viability status and treatment (A), apical myocardial viability status and treatment (B), and anterior or apical myocardial viability status and treatment (C). CABG, Coronary artery bypass grafting; $C I$, confidence interval; $S V R$, surgical ventricular reconstruction. 
included in this substudy also had scar on the anterior wall.

\section{Study Limitations}

In this study, SPECT imaging was the only modality used for assessing myocardial viability. Other commonly used tests (eg, delayed enhancement cardiac magnetic resonance imaging) have not been examined in the STICH trial. It is possible that the more detailed and quantitative myocardial scarring information provided by delayed enhancement imaging with magnetic resonance would prove useful in the selection of appropriate patients for SVR. This possibility deserves further investigation.

The SVR hypothesis of the STICH trial was not designed to examine the impact of viability determination on outcomes in these patients. The present observations are based on a post hoc analysis of a subset of STICH patients who underwent viability testing with SPECT. Thus, the impact of these observations is reduced compared with a trial specifically designed to address this issue. In addition, the reduced number of patients limits the statistical power of our findings. Finally, the decision to enroll patients in this trial could have been influenced by prior viability testing. However, it must be noted that the majority of patients in this report had viability testing performed after randomization.

\section{CONCLUSIONS}

In patients with $\mathrm{CAD}$ and severe regional $\mathrm{LV}$ dysfunction, assessment of myocardial viability does not identify patients who will benefit in terms of survival from adding SVR to CABG.

\section{References}

1. Jones RH, Velazquez EJ, Michler RE, Sopko G, Oh JK, O'Connor CM, et al. Coronary bypass surgery with or without surgical ventricular reconstruction. N Engl J Med. 2009;360:1705-17.

2. Velazquez EJ, Lee KL, O’Connor CM, Oh JK, Bonow RO, Pohost GM, et al. The rationale and design of the Surgical Treatment for Ischemic Heart Failure (STICH) Trial. J Thorac Cardiovasc Surg. 2007;134:1540-7.

3. Velazquez EJ, Lee KL, Deja MA, Jain A, Sopko G, Marchenko A, et al. Coronary-artery bypass surgery in patients with left ventricular dysfunction. N Engl J Med. 2011;364:1607-16.

4. Bonow RO, Maurer G, Lee KL, Holly TA, Binkley PF, Desvigne-Nickens P, et al. Myocardial viability and survival in ischemic left ventricular dysfunction. N Engl J Med. 2011;364:1617-25.

5. Dilsizian V, Bonow RO. Current diagnostic techniques of assessing myocardial viability in hibernating and stunned myocardium. Circulation. 1993;87:1-20.

6. Berman DS, Kiat H, Friedman J, Wang FP, van Train K, Matzer L, et al. Separate acquisition rest T1-201/stress Tc-99m sestamibi dual isotope myocardial perfusion SPECT: a clinical validation study. J Am Coll Cardiol. 1993;22:1455-64.

7. Sciagra R, Bisi G, Santoro GM, Zerauschek F, Sestini S, Pedenovi P, et al. Comparison of baseline-nitrate technetium-99m sestamibi with rest-redistribution thallium-201 tomography in detecting viable hibernating myocardium and predicting postrevascularization recovery. J Am Coll Cardiol. 1997;30:384-91.

8. Cerqueira MD, Weissman NJ, Dilsizian V, Jacobs AK, Kaul S, Laskey WK, et al. Standardized myocardial segmentation and nomenclature for tomographic imaging of the heart: a statement for healthcare professionals from the Cardiac Imaging Committee of the Council on Clinical Cardiology of the American Heart Association. Circulation. 2002;105:539-42.

9. Ragosta M, Beller GA, Watson DD, Kaul S, Gimple LW. Quantitative planar rest-redistribution 201Tl imaging in detection of myocardial viability and prediction of improvement in left ventricular function after coronary bypass surgery in patients with severely depressed left ventricular function. Circulation. 1993;87:1630-41.

10. Jones RH, White H, Velazquez EJ, Shaw LK, Pietrobon R, Panza JA, et al. STICH (Surgical Treatment for Ischemic Heart Failure) trial enrollment. J Am Coll Cardiol. 2010;56:490-8.

11. Buckberg G, Athanasuleas C. The STICH trial: misguided conclusions. J Thorac Cardiovasc Surg. 2009;138:1060-4.

12. Conte J. An indictment of the STICH trial: "True, true, and unrelated." J Heart Lung Transplant. 2010;29:492-6.

13. Athanasuleas CL, Buckberg GD, Stanley AW, Siler W, Dor V, Di Donato M, et al., for the RESTORE group. Surgical ventricular restoration in the treatment of congestive heart failure due to post-infarction ventricular dilation. J Am Coll Cardiol. 2004;44:1439-45.

\section{EDITORIAL COMMENTARY}

\section{Surgical ventricular restoration, myocardial viability, and your mother's fine china}

John M. Toole, MD

From the Division of Cardiothoracic Surgery, Medical University of South Carolina, Charleston, SC.

Disclosures: Author has nothing to disclose with regard to commercial support.

Received for publication Sept 26, 2014; accepted for publication Sept 28, 2014; available ahead of print Oct 18, 2014.

Address for reprints: John M. Toole, MD, Division of Cardiothoracic Surgery, Medical University of South Carolina, 25 Courtenay Dr, ART 7026, Charleston, SC 29425 (E-mail: toole@musc.edu).

J Thorac Cardiovasc Surg 2014;148:2684-5

$0022-5223 / \$ 36.00$

Copyright (c) 2014 by The American Association for Thoracic Surgery

http://dx.doi.org/10.1016/j.jtcvs.2014.09.099

See related article on pages $2677-84$.

Holly and colleagues ${ }^{1}$ present a post hoc analysis of the surgical arm of the Surgical Treatment for Ischemic Heart Failure (STICH) trial with hopes of shedding light on whether the presence or absence of myocardial viability alters outcomes after coronary artery bypass grafting $(\mathrm{CABG})$ and surgical ventricular reconstruction (SVR) compared with CABG alone. There are many criticisms of the STICH trial 


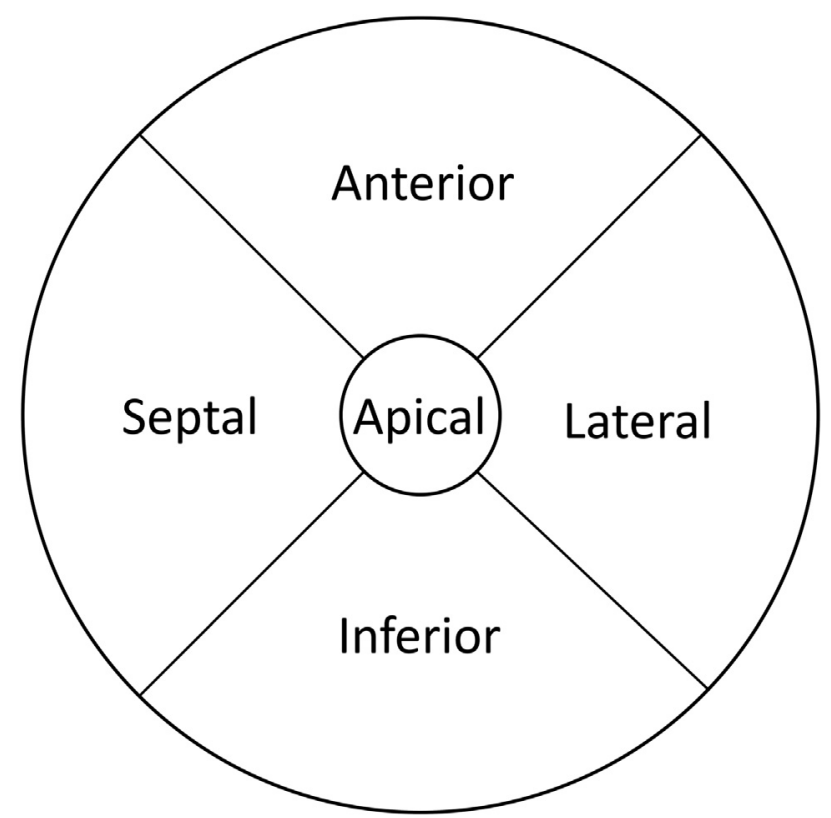

FIGURE E1. Five-segment model of the left ventricle used for analysis of regional viability. 